\title{
Does cancer education matter? Report on testicular cancer knowledge, awareness, and self-examination practice among young Polish men.
}

Łukasz Pietrzyk ( $\nabla$ lukasz.pietrzyk@wp.pl)

Uniwersytet Medyczny w Lublinie https://orcid.org/0000-0003-2931-5391

Marta Denisow-Pietrzyk

Uniwersytet Medyczny w Lublinie

Marcin Czeczelewski

Uniwersytet Medyczny w Lublinie

Konrad Ślizień-Kuczapski

Uniwersytet Medyczny w Lublinie

Kamil torres

Uniwersytet Medyczny w Lublinie

\section{Research}

Keywords: testicular cancer, testicular self-examination, medical education, medical simulation, adolescents, screening

Posted Date: July 29th, 2020

DOl: https://doi.org/10.21203/rs.3.rs-48530/v1

License: (c) (i) This work is licensed under a Creative Commons Attribution 4.0 International License. Read Full License 


\section{Abstract}

Background Testicular cancer (TC) is the most common malignancy and the third leading cause of cancer deaths in male adolescents and young adults. Early detection of testicular cancer can be achieved by testicular self-examination (TSE). To date, however, no population-based studies examined TC knowledge and practice of TSE among Polish men. The objective of the study was to assess the level of TC knowledge and awareness as well as the altitude and practice towards TSE among Polish male high school and medical students.

Methods A questionnaire survey was conducted in Poland with a representative sample of 1077 male students: 335 from high school and 742 medical students. An original questionnaire was designed as a multiple-choice question type and evaluated the participants' knowledge and awareness of TC, opinion and attitudes towards performing TSE.

Results The knowledge about TC epidemiology and the awareness of risk factors responsible for the TC was low. The knowledge of the signs and symptoms of TC was significantly higher among the medical students, compared to the high school students. The level of education was associated with the awareness of methods for early detection and symptoms of TC. A satisfactory level of awareness of the TSE practice was exhibited only by the medical students. The main reason for not performing selfexamination was the lack of knowledge and practical skills.

Conclusions The study reflects the deficiencies in health education among high school and medical students. The deficits of knowledge of TC in young men should motivate the education policy makers in Poland to implement education in the field of TC issues more widely in high schools. Moreover, cancer prevention modules and/or teaching methods should be improved in medical schools.

\section{Plain English Summary}

A cross sectional study was conducted to ass the knowledge and awareness of testicular cancer (TC) as well as the attitude and practice of testicular self-examination (TSE) among young males in Poland. Indeed, the study is the first report about TC and TSE in Polish population. The results indicated poor knowledge about the epidemiology, risk factors, signs and symptoms of TC. Moreover, the awareness of TSE as an important method for early diagnosis and cancer detection was very weak. The findings suggested the need of programs implementation aimed at improving the knowledge and awareness of TC and TSE.

\section{Background}

Testicular cancer (TC) is the most common malignancy and the third leading cause of cancer deaths in men between 15-40 years [1, 2]. It is a growing public health concern, as the incidence rates of TC have systematically increased worldwide in the last decades. Annually, 50,000 new cases and 10,000 deaths have been noticed globally [3]. Population-based epidemiological studies revealed ethnic differences in 
the TC epidemiology. The highest incidence rate was recorded among Caucasian individuals and in Nordic countries, where the incidence rates of TC were 10-fold higher compared to the Asian and African populations $[4,5]$.

Nowadays, there is no primary method to prevent TC $[5,6]$. The main cause of TC deaths results from a delayed diagnosis and detection of the cancer at an advanced metastatic stage [4, 6]. In the European population, the 5 -year survival rate is higher than $90 \%$ for TC patients being diagnosed at an early stage [7].

Early detection of testicular cancer has an important role in reducing the mortality, increasing the survival rates, and prognosis of the disease [7]. Early diagnosis can be achieved by testicular self-examination (TSE) [8]. Performing regular TSE may also have other benefits, i.e. men can become familiar with their own anatomy, gain knowledge how to detect and monitor the abnormalities other than cancer, and consider quicker contact with health care personnel to consult the detected anomalies [9]. However, the knowledge and awareness of TC and TSE is very poor among young men worldwide [10-12]. Interestingly, the gap in the knowledge is reported even among men that have completed the higher level of education, including health care or medical education [13].

Therefore, the primary purpose of strategies to prevent TC should be implementation of educational programs designed to increase awareness and knowledge [7]. Moreover, the programs should encourage men to be aware of pathological processes in male genitalia in order to reduce cancer-related deaths [6, 7]. Several national campaigns have already been undertaken to promote a healthier lifestyle and change on individual's behavior, i.e. 'Movember', which subsidized over 1,200 projects in about 20 countries. The projects were aimed at early detection of cancer, promotion of self-examination practices, and implementation of effective treatments $[14,15]$.

The aim of the study was to assess the level of testicular cancer knowledge and awareness as well as the altitude and practice towards testicular self-examination among Polish male high school and medical students.

\section{Methods}

\section{Study design and participants}

In total, 1077 male students from high schools $(n=335 ; H S)$ and medical university students $(n=742$; MS) were randomly selected to participate in the survey. The medical students were divided into two subgroups: 1. pre-clinical medical students (MS pre-clinical; first- to third-year students; $n=414$ ) and 2. clinical medical students (MS clinical; fourth- to six-year students; $n=328$ ). The participants came from different regions of Poland. The high school students attended public schools, and all medical students were members of the Faculty of Medicine of the Medical University of Lublin. 
The study involved completion of an original questionnaire created by a panel of experts (surgeons, urologist, pathologist, psychologist, and biostatistician). In designing the questionnaire, detailed literature review had been conducted. The questionnaire was designed as a multiple-choice question type. It consisted of 26 questions divided into 2 main parts. The first part (14 questions) aimed to assess the participants' knowledge and awareness of testicular cancer (TC), i.e. the epidemiology, cancer risk factors, signs and symptoms, and methods for early detection. Data concerning epidemiological statistics were drawn from the Cancer registry system in Poland and the study conducted by Park et al. $[16,17]$. The second part (12 questions) was designed to obtain students' opinion about testicular selfexamination (TSE), their attitudes towards performing TSE, and their willingness to get more knowledge of TC and TSE practice.

The study was conducted according to general ethical standards; the questionnaire was filled anonymously and voluntarily. The study was approved by the Ethical Committee of the Medical University of Lublin. Prior to the questionnaire distribution, the participants had been informed about the objectives of the study; additionally, the basic information about the aim of the study was provided at the top of the questionnaire. The time given to fill out the questionnaire was 20 minutes.

\section{Statistical analysis}

The participants' characteristics underwent a descriptive analysis. Continuous variables were presented as means \pm standard deviations (SD), and categorical variables were shown as the numbers and percentages of individuals. A two proportion Z-test was used to compare the answers of the groups of students concerning the knowledge of epidemiological facts, early diagnostic methods, risk factors, signs and symptoms, and reasons for not performing TSE. The frequency of TSE was compared between the groups using a Chi-square test for homogeneity. Differences with a p-value less than 0.05 were considered significant. The data were explored and analyzed using the RStudio ver. 1.1.463 software (Boston, MA, USA).

\section{Results}

\section{Characteristics of the male participants}

All students selected for the survey participated in the study, completed the questionnaire, and their answers were evaluated. The mean age of the participants was 19.4 years \pm 2.09 SD; range: $14-26$ years. The high school students accounted for $31.1 \%(n=335)$, while the medical students represented $68.9 \%(n$ $=742)$. In the group of the medical students, $55.8 \%(n=414)$ were attending their pre-clinical training and $44.2 \%(n=328)$ were from the clinical training subgroup. The majority $(87.2 \% ; n=292)$ of the high school students lived in villages or small towns $<10,000$ inhabitants. Among the medical students, $53.8 \%(n=$ 399) came from rural areas and $46.2 \%(n=343)$ from urban areas.

\section{Knowledge of TC}


The term 'testicular cancer' was easy to comprehend for $71.9 \%$ and $98.1 \%-100 \%$ of the high school medical students, respectively. The knowledge of TC epidemiological facts was low in both the high school and medical students (Fig. 1); however, a significantly greater number of correct answers were provided by the medical than high school students. The age group at risk for TC was correctly recognized by only $29.1 \%$ of the high school students and $48.5 \%$ of the medical students. The proportion of proper awareness of the morbidity of TC was very low, i.e. only $4.8 \%$ of the high school respondents and $9.4 \%$ of the medical students answered the question correctly.

The knowledge of the risk factors of TC is presented in Table 1. A low percentage (ca. 20-38\%) of the participants correctly identified a majority of well-known TC risk factors. The family history was well recognized by both the high school and medical students (65.7\% vs. $89.2 \%)$ among factors that may increase the risk of disease. A high proportion of the participants incorrectly defined several TC risk factors, i.e. poor hygiene of intimate areas (15.0\%-37.9\% of students) or the use of heated seats (22.4\%-26.1\% of students). Cryptorchidism was very poorly recognized as a TC predisposing factor; however, it was significantly more frequently indicated by the medical than high school students $(37.9 \%$ vs. $20.9 \%)$.

Table 1

Young men's knowledge of the TC risk factors; data are shown as percentages of selected answers that agreed with the statements regarding the increased risk of cancer development

\begin{tabular}{|c|c|c|c|c|c|c|c|}
\hline & $\begin{array}{l}\text { Risk factors for } \\
\text { testicular cancer }\end{array}$ & $\begin{array}{l}\text { HS } \\
(\%)\end{array}$ & $\begin{array}{l}\text { MS } \\
(\%)\end{array}$ & p & $\begin{array}{l}\text { Pre-clinical } \\
\text { MS (\%) }\end{array}$ & $\begin{array}{l}\text { Clinical } \\
\text { MS (\%) }\end{array}$ & $\mathbf{p}$ \\
\hline \multirow[t]{3}{*}{$\begin{array}{l}\text { Proven risk } \\
\text { factors }\end{array}$} & Cryptorchidism & 20.9 & 37.9 & $<.001$ & 38.2 & 37.5 & 0.913 \\
\hline & Family history of TC & 65.7 & 89.2 & $<.001$ & 91.5 & 86.3 & 0.029 \\
\hline & HPV infection & 32.5 & 29.6 & 0.378 & 28.7 & 30.8 & 0.599 \\
\hline \multirow[t]{4}{*}{$\begin{array}{l}\text { Unproven risk } \\
\text { factors }\end{array}$} & High sexual activity & 20.6 & 11.5 & $<.001$ & 11.6 & 11.3 & 0.986 \\
\hline & Androgyne intake & 21.8 & 9.0 & $<0.001$ & 6.3 & 12.5 & 0.005 \\
\hline & $\begin{array}{l}\text { Lack of intimate } \\
\text { places' hygiene }\end{array}$ & 37.9 & 15.6 & $<.001$ & 15.0 & 16.5 & 0.651 \\
\hline & Use of heated seats & 22.4 & 26.1 & 0.214 & 35.0 & 14.9 & $<.001$ \\
\hline \multicolumn{8}{|c|}{ HS - high school students; MS - medical students } \\
\hline
\end{tabular}


The level of education was clearly associated with the awareness of the methods for early detection of testicular cancer (Table 2). The awareness of TSE as a method for early detection of the pathology was very low among the high school students (only $25.1 \%$ of participants). A high number of both the high school and medical students indicated a visit to the doctor among the methods for early detection of TC (70.1\% vs. $67 \%$, respectively).

Table 2

Young men's knowledge of the testicular cancer diagnostic methods; data are shown as percentages of selected answers that agreed with statements regarding the acknowledged methods for TC early-stage detection

\begin{tabular}{|c|c|c|c|c|c|c|}
\hline $\begin{array}{l}\text { Method for early detection of } \\
\text { testicular cancer }\end{array}$ & $\begin{array}{l}\text { HS } \\
(\%)\end{array}$ & $\begin{array}{l}\text { MS } \\
(\%)\end{array}$ & $\mathbf{p}$ & $\begin{array}{l}\text { Pre-clinical } \\
\text { MS (\%) }\end{array}$ & $\begin{array}{l}\text { Clinical } \\
\text { MS (\%) }\end{array}$ & $\mathbf{p}$ \\
\hline $\begin{array}{l}\text { Medical visit and examination performed } \\
\text { by the physician }\end{array}$ & 70.1 & 67.0 & 0.337 & 62.6 & 73.8 & 0.001 \\
\hline Self-examination & 25.1 & 87.6 & $<.001$ & 89.4 & 85.4 & 0.126 \\
\hline Chest X-ray & 8.1 & 8.1 & 1 & 9.7 & 6.1 & 0.103 \\
\hline Urine test & 36.1 & 16.4 & $<.001$ & 16.7 & 16.2 & 0.932 \\
\hline \multicolumn{7}{|c|}{ HS - high school students; MS - medical students } \\
\hline
\end{tabular}

The knowledge of the signs and symptoms of TC was significantly higher among the medical students, compared to the high school students (Table 3). For example, the proportion of proper answers about the presence of a palpable mass in the testicle as an important symptom for TC was by ca. $20 \%$ higher in the group of the medical students than in the high school group. There was relatively low recognition of induration of the testicle (48.1\%) and scrotum enlargement (37.9\%) by high school students. The medical students were more aware of pathologies that can mimic testicular cancer, i.e. spermatocele, hydrocele, or varicocele (Table 4). 
Table 3

Young men's knowledge of testicular cancer signs and symptoms; data are shown as percentages of selected answers that agreed with statements regarding the common warning signs of TC

\begin{tabular}{|c|c|c|c|c|c|c|}
\hline $\begin{array}{l}\text { Symptoms of testicular } \\
\text { cancer }\end{array}$ & $\begin{array}{l}\text { HS } \\
(\%)\end{array}$ & $\begin{array}{l}\text { MS } \\
(\%)\end{array}$ & $\mathbf{p}$ & $\begin{array}{l}\text { Pre-clinical MS } \\
(\%)\end{array}$ & $\begin{array}{l}\text { Clinical } \\
\text { MS (\%) }\end{array}$ & p \\
\hline Palpable mass in the scrotum & 50.1 & 84.9 & $<.001$ & 87.0 & 82.3 & 0.099 \\
\hline $\begin{array}{l}\text { Induration, feeling of heaviness in the } \\
\text { scrotum }\end{array}$ & 48.1 & 82.3 & $<.001$ & 80.9 & 84.1 & 0.294 \\
\hline $\begin{array}{l}\text { Scrotum } \\
\text { enlargement }\end{array}$ & 37.9 & 66.7 & $<.001$ & 67.9 & 65.2 & 0.499 \\
\hline Testicular pain, discomfort & 46.3 & 16.2 & $<.001$ & 19.8 & 11.6 & 0.003 \\
\hline \multicolumn{7}{|c|}{ HS - high school students; MS - medical students } \\
\hline
\end{tabular}

Table 4

Young men's knowledge of pathologies mimicking testicular cancer; data are shown as percentages of selected answers that agreed with statements regarding pathologies that can mimic TC

\begin{tabular}{|c|c|c|c|c|c|c|}
\hline $\begin{array}{l}\text { Other pathologies mimicking testicular } \\
\text { cancer }\end{array}$ & $\begin{array}{l}\text { HS } \\
\text { (\%) }\end{array}$ & $\begin{array}{l}\text { MS } \\
\text { (\%) }\end{array}$ & $\mathbf{p}$ & $\begin{array}{l}\text { Pre-clinical MS } \\
(\%)\end{array}$ & $\begin{array}{l}\text { Clinical } \\
\text { MS (\%) }\end{array}$ & p \\
\hline Orchitis & 57.3 & 42.5 & $<.001$ & 35.7 & 50.9 & $<.001$ \\
\hline Spermatocele & 38.5 & 67.3 & $<.001$ & 70.5 & 63.1 & 0.039 \\
\hline Varicocele & 11.3 & 40.7 & $<.001$ & 42.3 & 38.7 & 0.367 \\
\hline Hydrocele & 35.8 & 49.7 & $<.001$ & 46.4 & 54.0 & 0.048 \\
\hline Groin hernia & 19.4 & 21.6 & 0.468 & 23.9 & 18.6 & 0.097 \\
\hline Twist of spermatic cord & 16.4 & 23.2 & 0.015 & 20.3 & 26.8 & 0.045 \\
\hline \multicolumn{7}{|c|}{ HS - high school students; MS - medical students } \\
\hline
\end{tabular}




\section{Students' knowledge and attitudes towards testicular self- examination (TSE)}

The awareness of testicular self-examination (TSE) as an important method for early diagnosis and cancer detection was very weak. A majority of the respondents $>80 \%$ of the high school respondents and $>50 \%$ of the medical school students) have never performed TSE (Fig. 2). Among the students who declared the TSE practice, the frequency of TSE was significantly higher in the group of medical students in comparison to group of high school students. However, the declared frequency of TSE was low; only $30 \%$ of the medical students and $9.9 \%$ of the high school students have practiced TSE once a month.

Figure 2. Young men's attitude towards testicular cancer self-examination; data are shown as a frequency of TSE

The most common reason for not performing TSE among both the high school and medical students was the lack of skills and knowledge how to perform the examination (Table 5). Greater numbers of the high school than medical students were afraid to detect cancer while performing self-examination (20.3\% vs. $11.6 \%$, respectively). In general, the students had a positive attitude towards TSE, and only 5.5-6.9\% declared that ethical issues were a barrier for regular self-check-ups. Only a small percentage of the respondents (5.1\% of the high school participants and $8.6 \%$ of the medicine students) have had the opportunity to attend professional training on TSE run by qualified teachers. A majority of the responders were willing to learn more about testicular cancer and testicular self-examination. 
Table 5

Young men's altitude towards testicular cancer self-examination; data are shown as percentages of selected answers that agreed with statements regarding the reasons for not performing of TSE

\begin{tabular}{|c|c|c|c|c|c|c|}
\hline $\begin{array}{l}\text { Reasons for not } \\
\text { performing testicular self- } \\
\text { examination }\end{array}$ & $\begin{array}{l}\text { HS } \\
(\%)\end{array}$ & $\begin{array}{l}\text { MS } \\
\text { (\%) }\end{array}$ & p & $\begin{array}{l}\text { Pre-clinical MS } \\
(\%)\end{array}$ & $\begin{array}{l}\text { Clinical } \\
\text { MS (\%) }\end{array}$ & p \\
\hline I do not know how to perform TSE & 63.0 & 45.6 & $<.001$ & 47.8 & 42.7 & 0.186 \\
\hline TSE is irrelevant & 19.7 & 28.6 & 0.003 & 18.1 & 41.8 & $\begin{array}{l}< \\
0.001\end{array}$ \\
\hline I am afraid of detecting cancer & 20.3 & 11.6 & $\begin{array}{l}< \\
0.001\end{array}$ & 11.1 & 12.2 & 0.732 \\
\hline I am ashamed of performing TSE & 8.4 & 7.5 & 0.736 & 9.7 & 4.9 & 0.021 \\
\hline Performing TSE is unethical & 6.9 & 5.5 & 0.470 & 4.6 & 6.7 & 0.275 \\
\hline \multicolumn{7}{|c|}{ HS - high school students; MS - medical students } \\
\hline
\end{tabular}

\section{Knowledge and attitudes expressed by pre-clinical vs. clinical medical students}

The evaluation of the medical students' knowledge showed differences between the pre-clinical and clinical individuals (Tables 1-4). For example, higher competence in answers concerning the morbidity of TC was demonstrated by the pre-clinical students, compared to their clinical counterparts $(11.6 \% \mathrm{vs} .6 .7 \%$, respectively); on the contrary, better knowledge of TC curability was shown by the clinical than pre-clinical group $(23.2 \%$ vs. $15.9 \%$, respectively).

A significantly higher proportion of the pre-clinical students than the clinical students recognized family history among the TC risk factors. Among the unproven risk factors, androgen was indicated as a TC risk factor significantly more frequently by the clinical students compared to the pre-clinical group $(12.5 \%$ vs. $6.3 \%$ ). In turn, the use of heated seats was indicated as an important factor in determination of the risk of TC by a higher proportion of the pre-clinical students than those in clinical training.

The answers to the question of the TC signs and symptoms were similar in both groups. However, a painless lump mass as a testicular cancer symptom was indicated significantly more often by the clinical students compared to the pre-clinical group ( $44.5 \%$ vs. $28.5 \%)$.

\section{Discussion}


The study of young males' knowledge and awareness of TC is highly relevant, as the rate of the TC incidence exhibits a constant rising tendency worldwide, including Poland $[17,18]$. Increasing awareness of risk factors, TC signs and symptoms, and methods for early diagnosis in young males is a significant part of the strategy for a decrease in TC morbidity and mortality [1].

To our knowledge, the present study is the first report assessing the knowledge and awareness of TC as well as the attitude and practice of TSE among young males in Poland. Here we used a self-designed questionnaire to compare the knowledge and attitudes of high school and university medical students in order to forward the information about possible knowledge gaps to the appropriate authority and health policy-makers. Moreover, we analyzed the awareness of medical students at remarkably different levels of medical education to identify inadequacies in their knowledge of TC for development of better education curricula.

In our study, the percentage of participants that had heard about testicular cancer was quite satisfying (70\%-100\%); nevertheless, the knowledge of the epidemiology and the awareness of risk factors responsible for the TC were low; only $30-50 \%$ of the respondents recognized these issues properly. The analysis of the literature showed that young males' knowledge of TC varied. Sugisaki et al. presented data suggesting that even ca. $50 \%$ of high school male respondents have never heard about TC [19]. Studies conducted in different world regions have highlighted a relatively low level of young males' awareness of TC, epidemiological facts and risk factors, as well as signs and symptoms $[4,10,20]$. Awareness of epidemiology and perception of risks are very important, as they are usually associated with motivation to reduce a possible danger and reinforce changes in behavior. They can also stimulate actions towards direct prevention and control, i.e. self-examination. Equally important, the consciousness that TC is a curable cancer should encourage young males to attend primary care service at an earlier stage, potentially improving the odds of survival and the financial aspect of health care related to more cost-effective treatment.

Our study showed inadequate knowledge of the well-known risk factors for testicular cancer. Regrettably, a high percentage of the participants defined the TC risk factors incorrectly, i.e. indicating poor hygiene of intimate areas or use of heated seats among possible risks for TC. In Northern Ireland, males aged 18-45 years, also falsely recognized TC risk factors, i.e. specifying body weight (44\% of respondents) or alcohol drinking (21\% of respondents) [14]. Unfortunately, the awareness of cryptorchidism, which is a wellknown risk factor for testicular cancer, was unsatisfying among our study population. Similarly, Vadaparampil et al. reported very low awareness of the link between cryptorchidism and TC [21]. This testicular abnormality is one of the most strongly established TC risk factors [22]. It has been proven that a personal history of cryptorchidism can increase the risk of TC up to 8-fold [23]. Therefore, it is particularly important to improve and raise students' awareness of risks associated with an undescended testicle.

A low level of awareness of young age as a risk factor for TC was revealed, which is particularly disappointing. Various reports have indicated that young male students are unaware of being in the age- 
risk group for TC, which is the most common neoplasm in 15-35 year age group [14, 24, 25]. Presumably, young men are not very conscious of cancer and their perception of malignant pathologies is associated only with older people [26].

It is optimistic that the family history of TC was indicated as a predisposing factor for developing TC. Men with a family history of TC have an approx. 4-9 times greater risk of TC [21]. The awareness and cancer-related concern deriving from family history may function as a facilitator of preventive behavior and should mobilize men to practice regular self-examination. Regular TSE is recommended by National Cancer Societies worldwide for men with a known family history to increase the chance of early detection of TC $[27,28]$.

Our participants displayed no clear understanding of the signs and symptoms for TC. There was a high recognition of i.e. palpable mass in the testicle, induration of the testicle, or scrotum enlargement. Regrettably, the other crucial TC symptoms were recognized less often. Surveys conducted by various researchers also show that the percentage of correct answers concerning the early symptoms of TC fluctuates and seems to be unsatisfactory. Braga et al. found that only about $42 \%$ of Portuguese male respondents indicated to the most common TC signs and symptoms correctly [24]. Roy et al. documented that less than $30 \%$ of Irish men properly recognized the first symptoms of the disease [14]. Even lower awareness of the first TC signs was reported among Nigerian respondents, i.e. a lump in the testicle was identified by only ca. $10 \%$ of males. Moreover, they were not able to identify any other potential signs and symptoms of testicular malignancy [13]. Our survey and the study mentioned above emphasized that the low awareness of TC signs and symptoms derive from gaps in cancer education.

Self-examination is a beneficial tool to detect testicular cancer at an early stage, which gives a chance for a relatively high cure rate. It is estimated that ca. $90 \%$ of malignant testicular pathologies are detected by males performing regularly self-examination [29]. Therefore, it is important for young men to be aware of the possibility of early TC detection and to know how to perform a checkup. The high level of awareness of the TSE practice was characteristic only for our medical students. In general, the literature reports indicate that the state of knowledge and awareness related to testicular self-examination in the young male population is insufficient. For example, TSE is regularly performed by $2 \%$ of young men in Denmark, $1.9 \%$ of young males in Turkey, $8.5 \%$ of males in Iran, $12.3 \%$ of male students in France [9, 30-32]. The testicular self-examination was found to be most popular among British, Irish, and Hungarian students; however, the rate is still very low, with only ca. $25 \%$ of individuals performing TSE [11, 33]. Therefore, it is crucial to promote and develop the awareness about TSE as an early cancer detection method in young adult men. The main reason for not performing self-examination was the lack of knowledge and practical skills. However, $85 \%$ of our students are willing to learn more about the methods for testicular cancer prophylaxis [32,34]. Similarly, our students never tried to perform TSE due to the lack of knowledge how it should be done. The importance of professional training on the TSE practice was revealed in the United Kingdom and the United States, where the TSE performance ratio among male college students increased from 58.4 to $69.3 \%$ and from $9-36 \%$, respectively, after practical professional training [30, 35]. It should be emphasized that the most effective education programs on testicular self-examination should match 
the age and the educational level of the recipients. It is crucially important that programs regarding male genital diseases should be prepared and conducted by well-trained teachers, who should employ interactive tools instead of standard theoretical training [15]. Moreover, the teachers should be empathic and avoid cheeky humor or jokes regarding genitals [31].

In general, our study reflects the deficiencies in health education among high school and medical students. As expected, the high school students had poorer knowledge and awareness of the epidemiological facts, risk factors, signs and signals of TC, and TSE than the medical students. Many studies demonstrated that the education level was a major determinant of cancer knowledge, and increased awareness was associated with a higher level of education [14,24,36]. The awareness of cancer can be also associated with several other factors, i.e. income, ethnicity, or social position [37].

It is worth mentioning that our pre-clinical students were more conscious of the TC incidence rate, age risk group, and morbidity than the clinical students. At the Medical University in Lublin, as in other medical universities, the pre-clinical modules consist of basic sciences (i.e. anatomy, histology, physiology, epidemiology and hygiene, pathomorphology, and pathophysiology). They are focused on teaching the pathology of diseases, epidemiology, disease prevention, population health, and health promotion [38]. In the clinical stage, the students are exposed to patients in different hospital wards, gain history-taking competence, and have an opportunity to acquire clinical skills. Various experiments have revealed that medical students forget ca. $25-35 \%$ of basic science knowledge after 1 year and more than $50 \%$ after the following year $[39,40]$. Cancer is a major public health problem; therefore, medical students are expected to remember details of the disease for a longer time. Therefore, there are several possible approaches to consider in order to increase the medical students' knowledge: (i) the module programs should be rearranged, (ii) more emphasis should be placed on cancer epidemiology, risk factors, and prevention, (iii) teaching should be remodeled and more attention should be paid to practical skills, (iv) teachers have to improve their teaching methods by implementation of i.e. simulation techniques, clinical cases, or problem-based teaching. However, equally important is that students have to be mobilized to advance their learning methods.

\section{Limitations}

It has to be emphasized that our study has several limitations. First, the data were collected in only one region of Poland. Secondly, the medical students attended only one medical school. Third, the study was performed using self-designed questionnaire. However, according to our knowledge there is lack of standardized questionnaire assessing cancer knowledge. Hence, the experience of the participants may not fully reflect what may be obtainable in the general population of young man. However, the survey shows preliminary data that can be useful in the design of further testicular cancer programs and services.

\section{Conclusions}


Our study has revealed that the level of knowledge of TC among students, including medical students, is not satisfying. Therefore, it is still a great task for health education with respect to TC and efforts should be made to construct programs aimed at improving the knowledge and awareness of TC. Raising the awareness of TC among most at-risk young men may reduce the fear of development of TC cancer and change the attitude towards the first signs and symptoms as well as self-examination, which may contribute to early diagnosis. Schools are a valuable asset in health education, and cancer prevention modules should be included in school curricula.

\section{Abbreviations}

TC - testicular cancer

TSE - testicular self-examination

MS - medical students

HS - high school

\section{Declarations}

\section{Ethics approval and consent to participate}

The ethics committee of Medical University of Lublin approved the study.

\section{Consent for publication}

Not applicable.

\section{Availability od data and materials}

The datasets analysed during the current study are available from the corresponding author on reasonable request.

\section{Competing interest}

The authors declare no conflict of interests.

\section{Funding}

The study was supported by the grant no. DS205 and MNmb230.

\section{Authors' contributions}

Conceptualization, Ł.P., K.T., M.D.-P.; Methodology, Ł.P., M.D.-P.; Formal Analysis, M.C., Ł.P.; Investigation, Ł.P.; Resources, Ł.P., M.D.-P.; Writing - Original Draft Preparation, Ł.P. K.Ś.-K., M.C. M.D.-P.; Writing - 
Review \& Editing, Ł.P., K.T.; Visualization, M.C., K. Ś.-K.; Supervision, Ł.P., K.T.; Funding Acquisition, K.T., Ł.P. All authors have read and agreed to the version of the manuscript.

\section{Acknowledgments}

We are grateful for Dr. Grzegorz Witkowski, MSc., Ph.D. for helping during questionnaires distribution among the participants.

\section{References}

[1] Pierorazio PM, Albers P, Black PC, et al. Non-risk-adapted Surveillance for Stage I Testicular Cancer: Critical Review and Summary. Eur Urol 2018;73:899-907.

[2] Shanmugalingam T, Soultati A, Chowdhury S, et al. Global incidence and outcome of testicular cancer. Clin Epidemiol 2013;5:417.

[3] Valipour AA, Mohammadian M, Mohammadian-Hafshejani A, et al. Forecasting the Incidence of Testis Cancer in Europe from 2012-2035. Iran J Public Health 2017;46:1448.

[4] Park JS, Kim J, Elghiaty A, et al. Recent global trends in testicular cancer incidence and mortality. Medicine (Baltimore) 2018;97.

[5] Salehiniya H, Farmanfarma KK, Mahdavifar N, et al. Testicular cancer in the world: an epidemiological review. World Cancer Research Journal 2018; 5 (4): e1180. n.d.

[6] Drevinskaite M, Patasius A, Kincius M, et al. A Population-Based Analysis of Incidence, Mortality, and Survival in Testicular Cancer Patients in Lithuania. Medicina (B Aires) 2019;55:552.

[7] Siegel R, DeSantis C, Virgo K, et al. Cancer treatment and survivorship statistics, 2012. CA Cancer J Clin 2012;62:220-41.

[8] Fadich A, Giorgianni SJ, Rovito MJ, et al. USPSTF Testicular Examination Nomination-SelfExaminations and Examinations in a Clinical Setting. Am J Mens Health 2018;12:1510-6.

[9] Rovito MJ, Leone JE, Cavayero CT. “Off-Label” Usage of Testicular Self-Examination (TSE): Benefits Beyond Cancer Detection. Am J Mens Health 2018;12:505-13.

[10] Atuhaire C, Byamukama A, Cumber RY, et al. Knowledge and practice of testicular self-examination among secondary students at Ntare School in Mbarara District, South western Uganda. Pan Afr Med J 2019;33.

[11] Wardle J, Steptoe A, Burckhardt R, et al. Testicular Self-Examination: Attitudes and Practices Among Young Men in Europe. Prev Med (Baltim) 1994;23:206-10. 
[12] Ugurlu Z, Akkuzu G, Karahan A, et al. Testicular cancer awareness and testicular self-examination among university students. Asian Pac J Cancer Prev 2011;12:695-8.

[13] Ugboma HAA, Aburoma HLS. Public awareness of testicular cancer and testicular self-examination in academic environments: a lost opportunity. Clinics 2011;66:1125-8.

[14] Roy RK, Casson K. Attitudes Toward Testicular Cancer and Self-Examination Among Northern Irish Males. Am J Mens Health 2017;11:253-61.

[15] Akar erife Z., Bebi H. Evaluation of the effectiveness of testicular cancer and testicular selfexamination training for patient care personnel: intervention study. Health Educ Res 2014;29:966-76.

[16] Cancer registry system in Poland. Testicular cancer. Available at: http://onkologia.org.pl/rak-jadra/.

[17] Lin K, R S. Screening for Testicular Cancer: An Evidence Review for the U.S. Preventive Services Task Force. Ann Intern Med 2010;153:396.

[18] Stawińska-Witoszyńska B, Wojtyła-Buciora P, Więckowska B, et al. Malignant testicular tumour incidence and mortality trends. Contemp Oncol 2016;20:58.

[19] Sugisaki K, Ueda S, Monobe H, et al. Cancer understanding among Japanese students based on a nationwide survey. Environ Health Prev Med 2014;19:395-404.

[20] Peters JA, Beckjord EB, Banda Ryan DR, et al. Testicular Cancer and Genetics Knowledge Among Familial Testicular Cancer Family Members. J Genet Couns 2008;17:351-64.

[21] Vadaparampil ST, Moser RP, Loud J, et al. Factors associated with testicular self-examination among unaffected men from multiple-case testicular cancer families. Hered Cancer Clin Pract 2009;7:11.

[22] Ferguson L, Agoulnik Al. Testicular Cancer and Cryptorchidism. Front Endocrinol (Lausanne) 2013;4.

[23] Kinkade S. Testicular cancer. Am Fam Physician 1999;59:2539-44, 2549-50.

[24] Braga IC, Cabral J, Louro N, et al. Testicular Cancer Awareness and Knowledge: Is It the Same? Exploratory Study in a Mixed-Gender Population. J Cancer Educ 2017;32:105-11.

[25] Ugwumba FO, Ekwueme OEC, Okoh AD. Testicular Cancer and Testicular Self-Examination; Knowledge, Attitudes and Practice in Final Year Medical Students in Nigeria. Asian Pac J Cancer Prev 2016;17:4999-5003.

[26] Cronholm PF, Mao JJ, Nguyen GT, et al. A Dilemma in Male Engagement in Preventive Services: Adolescent Males' Knowledge and Attitudes Toward Testicular Cancer and Testicular Self-Exam. Am J Mens Health 2009;3:134-40. 
[27] Polish Urological Association. Home page. Available at: https://www.pturol.org.pl/.

[28] American Urological Association. Home page. Available at: https://www.auanet.org/.

[29] Avci IA, Altinel B. The Validity and Reliability of Health Belief Scale for Testicular Cancer SelfExamination. Am J Mens Health 2018;12:531-8.

[30] McCullagh J, Lewis G, Warlow C. Promoting awareness and practice of testicular self-examination. Nurs Stand 2005;19:41-50.

[31] Thornton CP. Best Practice in Teaching Male Adolescents and Young Men to Perform Testicular Self-Examinations: A Review. J Pediatr Heal Care 2016;30:518-27.

[32] Lechner L, Oenema A, de Nooijer J. Testicular self-examination (TSE) among Dutch young men aged 15-19: determinants of the intention to practice TSE. Health Educ Res 2002;17:73-84.

[33] Özbaş A, Çavdar İ, Fındık ÜY, et al. Inadequate knowledge levels of Turkish male university students about testicular self-examination. Asian Pac J Cancer Prev 2011;12:919-22.

[34] Evans REC, Steptoe A, Wardle J. Testicular self-examination: change in rates of practice in European university students, from 13 countries, over a 10-year period. J Men's Heal Gend 2006;3:36872.

[35] Dachs RJ, Garb JL, White C, et al. Male college students' compliance with testicular selfexamination. J Adolesc Heal Care 1989;10:295-9.

[36] Pietrzyk $\measuredangle$, Torres A, Denisow-Pietrzyk $M$, et al. What Do We Know About Education in Colorectal Cancer Prevention?-Survey Among 1130 Medical Students. J Cancer Educ 2017;32:406-12.

[37] Saab MM, Davoren M, Murphy A, et al. Promoting men's awareness, self-examination, and helpseeking for testicular disorders: a systematic review of interventions. HRB Open Res 2018;1.

[38] Weggemans MM, Custers EJFM, ten Cate OTJ. Unprepared Retesting of First Year Knowledge: How Much Do Second Year Medical Students Remember? Med Sci Educ 2017;27:597-605.

[39] Custers EJFM. Long-term retention of basic science knowledge: a review study. Adv Heal Sci Educ 2010;15:109-28.

[40] Anderson J. The Continuum of Medical Education: The Role of Basic Medical Sciences. J R Coll Physicians Lond 1993;27:405.

\section{Figures}




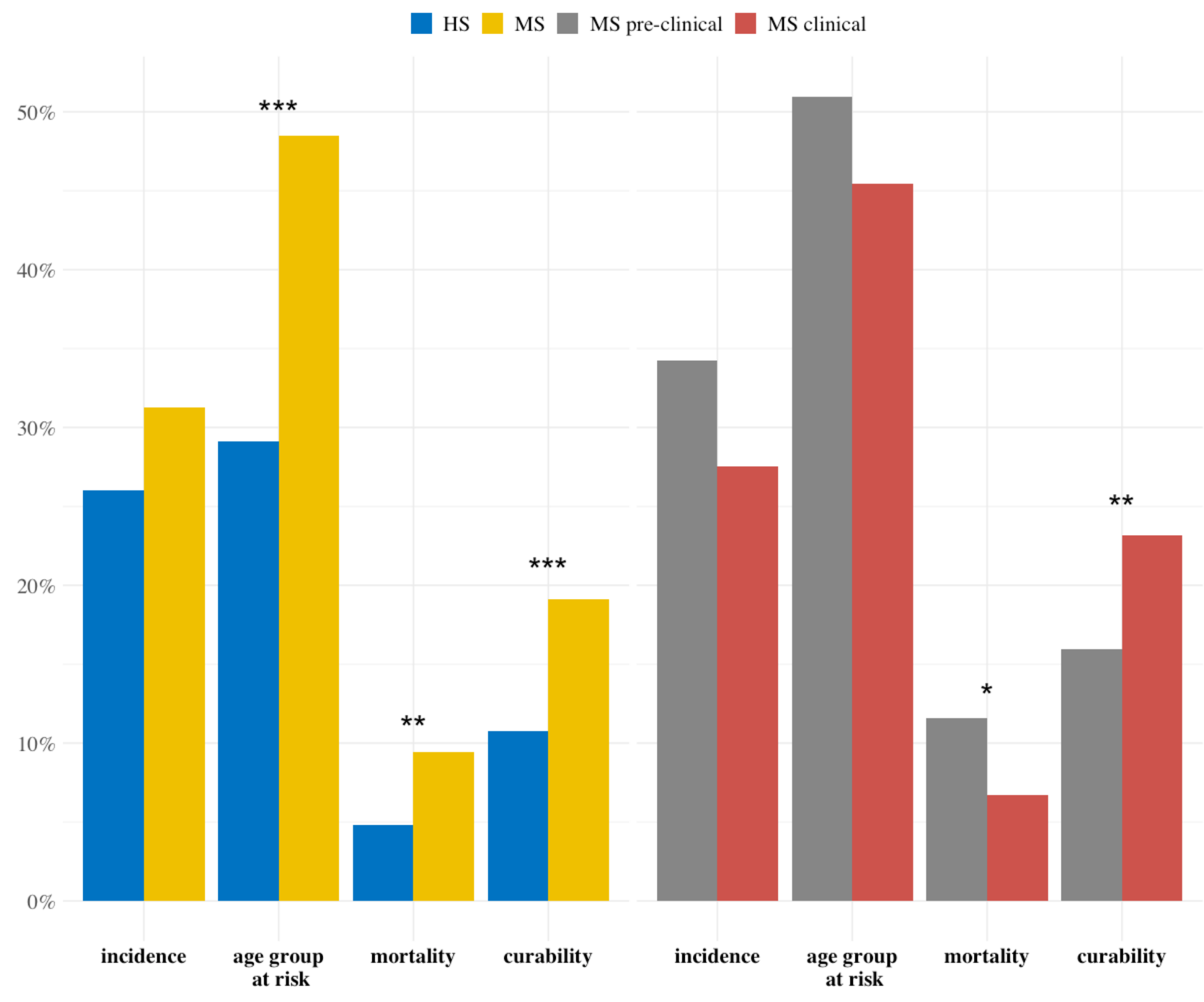

\section{Figure 1}

Young men's knowledge of the epidemiological statistics concerning testicular cancer; data are shown as a percentage of correct responses * $p \leq 0.05 ;{ }^{* \star} p \leq 0.01 ; * \star \star p \leq 0.001$; Current statistics: incidence in Europe: 5.6 per 100,000; age group at risk: $15-44$ years; mortality in Europe: 0.4 per 100,000; curability: more than $90 \%$ if detected at an early stage 
$80 \%$

$60 \%$

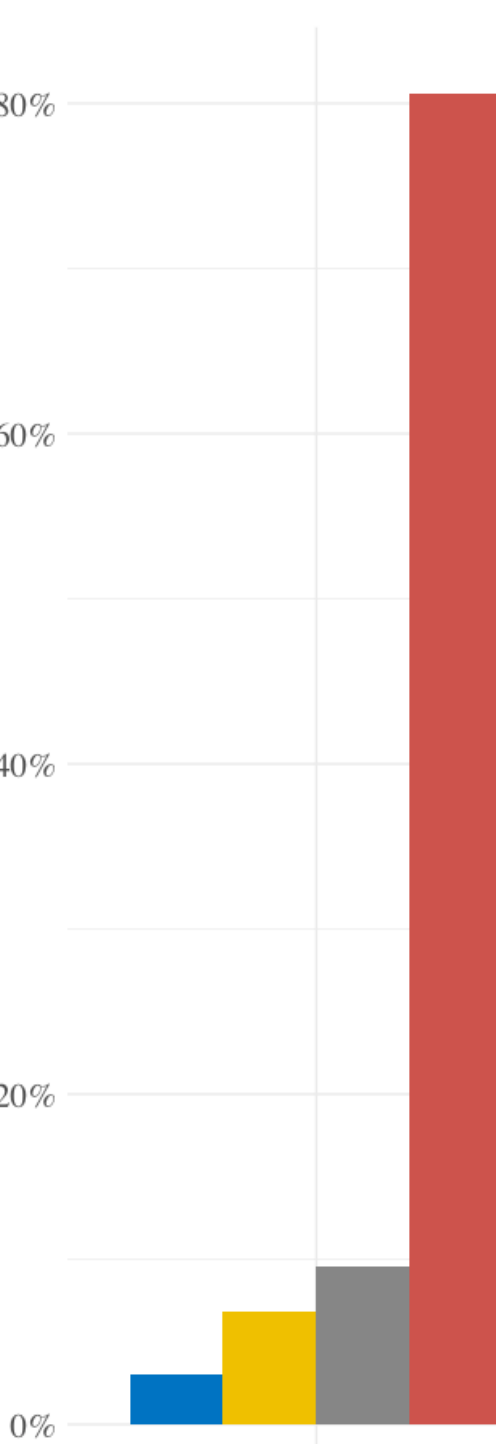

HS

MS

MS pre-clinical

MS clinical

Figure 2

Young men's attitude towards testicular cancer self-examination; data are shown as a frequency of TSE 